\title{
ARTIGO
}

\section{NEUROCIÊNCIAS PARA ESTUDANTES: O LIVRO DIDÁTICO E PROJETOS DE INTERVENÇÃO}

Neuroscience for students: the textbook and intervention projects

Neurociencias para estudiantes: el libro didáctico y proyectos de intervención

Mauren dos Santos Oliveira

Universidade Federal do Rio Grande - Brasil

Fernanda Antoniolo Hammes de Carvalho

Universidade Federal do Rio Grande - Brasil

\begin{abstract}
Resumo
$\mathrm{Na}$ adolescência, o jovem vivencia uma fase de questionamentos acerca de sua identidade e de seu futuro e a autopercepção tem papel significativo nos comportamentos a serem adotados. O texto tem como escopo promover uma reflexão acerca da possibilidade de ampliar a autopercepção nos adolescentes através da exploração do conteúdo científico na área de neurociências. Tem-se como premissa o fato de que o conhecimento neurocientífico, ao propiciar um melhor entendimento do funcionamento do cérebro quando atrelado a situações cotidianas, tanto no âmbito cognitivo como social, pode contribuir para mudanças conceituais, as quais podem passar a constituir referencial para alterações comportamentais. Nesse sentido, a educação formal pode contribuir significativamente, tendo como alternativas a inserção dos conteúdos nos livros didáticos, em especial na área de biologia e programas de intervenção.
\end{abstract}

Palavras-chave: Autopercepção do adolescente. Neurociências. Projetos de intervenção.

\begin{abstract}
During adolescence, the young experience a time of questioning about their identity and their future, and self-perception has a significant role in the behaviors being adopted. The text aims to promote thinking about the possibility of enlarging the perception adolescents have about themselves through the exploration of scientific knowledge in the neuroscience area. By providing a better understanding of how the brain works when it is bound to everyday situations, in both cognitive and social contexts, this can contribute to conceptual changes which might become a reference for behavioral alterations. In this sense, formal education can significantly contribute by including school subjects in the textbooks, particularly in the area of Biology and intervention programs.
\end{abstract}

Keywords: Adolescent's self-perception. Intervention projects. Neuroscience. 


\section{Resumen}

En la adolescencia, el joven experimenta una etapa de cuestionamientos acerca de su identidad y de su futuro $\mathrm{y}$, la autopercepción tiene un papel significativo en los comportamientos que serán adoptados. El texto tiene como objetivo promover una reflexión acerca de la posibilidad de ampliar la autopercepción en los adolescentes a través de la exploración del contenido científico en el área de neurociencias. Se tiene como primicia el hecho de que el conocimiento neurocientífico, al propiciar un mejor entendimiento del funcionamiento del cerebro cuando ligado a situaciones cotidianas, tanto en el ámbito cognitivo como en el social, puede contribuir a mudanzas conceptuales, las cuales pueden pasar a constituir referencia para alteraciones de comportamientos. En ese sentido, la educación formal puede contribuir significativamente, teniendo como alternativas la introducción de los contenidos en los libros didácticos, en especial en el área de biología y programas de intervención.

Palabras clave: Autopercepción del adolescente. Neurociencias. Proyectos de intervención.

\section{Introdução}

Vários são os desafios enfrentados pelos docentes nas escolas no que se refere ao aluno adolescente. Estudantes que, apesar de um maior domínio da linguagem, da flexibilidade cognitiva ampliada e de capacidades motoras mais acuradas, passam por um período um tanto quanto "conturbado".

A adolescência é uma etapa compreendida entre a infância e a fase adulta, marcada por situações de autoconhecimento, autocrítica, questionamento de valores e influência na sociedade. Conforme o Estatuto da Criança e do Adolescente (BRASIL, 1990), a adolescência é demarcada entre as idades de 12 a 18 anos. Para Cloutier e Drapeau (2012), os limites exatos para o período da adolescência são difíceis de estabelecer, pois podem diferir dependendo da dimensão do desenvolvimento considerada, seja ela biológica, psicológica ou social, na qual o adolescente encontra-se inserido.

Melo e Cruz (2012) retomando os estudos de Hall (1844-1924), considerado o pai da "psicologia da adolescência", destacam a ideia de que o desenvolvimento na adolescência se processa por fatores fisiológicos geneticamente determinados, que direcionam e controlam o desenvolvimento, o crescimento e o comportamento. Considerado o primeiro psicólogo a distinguir a psicologia da adolescência como campo de conhecimento e a se utilizar de métodos científicos para estudá-la, Hall, em sua teoria, defendia que os comportamentos acontecem dentro de um padrão inevitável, inalterável e universal. A adolescência seria uma fase de "tempestade e tensão" e um momento de "renascimento das características mais elevadas e mais plenamente humanas". 
Realmente trata-se de uma época de contrastes, de alterações comportamentais que até então estavam atreladas somente à influência hormonal da puberdade, mas que hoje é objeto de estudo no campo das neurociências e, recentemente, atribuiu-se também às alterações na estrutura do cérebro ainda em desenvolvimento algumas características dessa fase. Avanços nas pesquisas neurocientíficas, tornou possível observar que o cérebro do adolescente sofre uma reorganização química e estrutural, sendo essa, substrato para as mudanças cognitivas e comportamentais desse sujeito. No entanto, apesar do papel significativo da biologia, de acordo com a neurociência, fatores ambientais também influenciam na fisiologia do cérebro; o córtex pré-frontal, por exemplo, área responsável pelo planejamento, pensamento complexo e modulação do comportamento, é modificada também por processos de mediação, como aqueles que ocorrem junto aos pais e professores.

Nota-se que os comportamentos característicos dessa fase do desenvolvimento humano acabam por ter implicações no campo da educação, pois os adolescentes são comumente estudantes que exigem uma grande flexibilidade por parte do docente, gerando muitas vezes uma relação marcada por tensões e dilemas. A indisciplina, a falta de respeito para com os professores e entre colegas, o bullying, o uso de drogas, assim como atitudes que apontam a ausência de um compromisso com a própria aprendizagem, podem ser considerados fatores problemáticos no ambiente escolar.

Por outro lado, é justamente devido a essa reorganização que a adolescência seria mais uma fase, além da infância, em que as interações humanas vivenciadas, seja no contexto familiar ou escolar, podem exercer grande influência sobre os caminhos que o cérebro em reestruturação toma - positiva ou negativamente. Nos Estados Unidos e no Reino Unido, por exemplo, é crescente o número de projetos com abordagens nessa linha de pensamento. São propostas fundamentadas na ideia de que existem métodos, por meio dos quais a escola pode aumentar a consciência das próprias emoções no aluno, colaborando para que, autogerenciando os sentimentos, os estudantes aprendam a lidar saudavelmente com os conflitos.

Além disso, o livro didático na área de biologia, em especial, pode ser ferramenta útil para propiciar um esclarecimento mais adequado para o aluno adolescente acercade como seu cérebro se encontra nessa fase e quais as transformações geradas nesse momento, colaborando para melhorar a autopercepção.

Desse modo, a educação pode ser instrumento significativo no processo da transformação social do indivíduo, no sentido não só promover uma formação que envolva competência científica, mas também proporcionar um processo educativo que prepare o 
indivíduo para melhor conhecer o mundo com o qual interage e para o entendimento de si mesmo como sujeito que se autorreorganiza permanentemente e que pode, pois, optar por determinada forma de participação no contexto em que vive.

\section{Autopercepção no adolescente}

Para Cloutier e Drapeau (2012), o contexto social exige que o jovem adolescente passe a se comportar como adulto com noções de responsabilidade, dever e autonomia, movido por suas próprias demandas. Sendo assim, tornar-se autônomo seria adquirir todo um conjunto de habilidades para viver de modo independente com capacidade de tomar decisões de maneira individual. Há três tipos de autonomia a serem consideradas: a autonomia emocional, com a qual o jovem teria o controle de suas emoções e sentimentos, a autonomia comportamental, baseada no controle das ações e consequências e a autonomia ideológica, caracterizada pelo controle de valores e ideias.

Vários são os desafios enfrentados nessa etapa do desenvolvimento humano. Seus comportamentos, ações, reações, angústias, conflitos durante essa fase são típicas de um cérebro diferente, tanto do cérebro infantil quanto do adulto, e que justificam essa alteração comportamental. Trata-se de uma etapa compreendida entre a infância e a fase adulta, marcada por situações de autoconhecimento, autocrítica, questionamento de valores e influência na sociedade.

Pesquisas recentes com técnicas de imageamento cerebral já permitem aos pesquisadores mostrar que o cérebro do adolescente sofre algumas reorganizações química e estrutural, sendo essas, substratos para as mudanças cognitivas e comportamentais desse sujeito. Ou seja, seus comportamentos característicos não seriam meramente resultado da influência hormonal que marca a puberdade; seriam, ainda, alterações no desenvolvimento de seu cérebro. O gosto pelo perigo, o afastamento da família, as novas amizades, o desenvolvimento cognitivo e emocional que caracterizam o adolescente são vistos pela neurociência como etapas necessárias à conquista de sua independência na fase adulta.

A adolescência é um período de crescimento no qual o indivíduo precisa realizar diversas tarefas para efetuar a passagem da infância à vida adulta. Essas tarefas estão relacionadas a algumas mudanças características deste período, sendo que as alterações cognitivas e comportamentais estão sob efeito dos diferentes momentos maturacionais do cérebro. 
Nessa fase da vida, inicia-se um processo de redução de sinapses, isto é, das comunicações entre os neurônios, chamada por alguns pesquisadores de "lei da selva" cerebral. Ou seja, as sinapses que não são usadas, são eliminadas e permanecem apenas as mais usadas para a formação de circuitos neuronais mais eficientes. Estudos também comprovam que no processo da infância até a adolescência há um aumento na substância branca (axônios dos neurônios) e uma redução da massa cinzenta (corpos celulares dos neurônios) juntamente com um processo de mielinização neuronal. A mielinização das conexões, formação da capa de gordura que age como isolante elétrico das fibras nervosas propicia a transmissão mais rápida de sinais nervosos entre regiões cerebrais. Com isso, há melhora no domínio da linguagem pelo adolescente e nas funções executivas, como atenção e memórias de trabalho, aprimorando e agilizando suas respostas motoras e cognitivas. (BOYD; BEE, 2011; GAZZANIGA; HEATHERTON, 2005).

Atualmente, sabe-se que alterações no sistema límbico - também conhecido como sistema de recompensa -, são responsáveis pela necessidade do adolescente de correr riscos. O sistema de recompensa, caracterizado pelo conjunto de estruturas no cérebro responsáveis pelo prazer que é obtido conforme a quantidade de dopamina liberada, sofre uma queda na fase da adolescência. Ou seja, o que antes através da motivação gerava a liberação de grande quantidade de dopamina na criança, agora perde em grande quantidade na adolescência. A perda de receptores para a dopamina no sistema de recompensa na adolescência é crucial para o comportamento adolescente e para o chamado tédio que os invade pela perda de motivação do que antes lhes era de extrema relevância (HERCULANO-HOUZEL, 2005).

$\mathrm{O}$ crescimento de membros posteriores e anteriores de forma desordenada também promovem modificações no mapa somatossensorial do cérebro adolescente. Entretanto, o crescimento desigual do corpo não só demanda ajustes no córtex parietal, como altera a autopercepção do corpo, fato esse que gera um estranhamento do adolescente com o seu corpo trazendo à tona a busca por novos estilos na vestimenta, nas maquiagens, nos acessórios, na procura do seu eu (HERCULANO-HOUZEL, 2005). Conforme Boyd e Bee (2011, p. 401), “devido a essa assimetria é comum acharmos que um adolescente é 'desajeitado' ou 'descoordenado"'.

O período final da adolescência é marcado por uma maior maturidade e competência regulatória, influenciada pela maturação dos lóbulos frontais e pré-frontais do cérebro. $\mathrm{O}$ córtex frontal é a última estrutura a amadurecer ocasionando uma estabilização do volume de massa cinzenta, o que ocorre em torno dos 22 anos de idade, sendo que é possível se estender até os 30 anos. Atribui-se a isso, o comportamento proativo e o maior desenvolvimento de um 
cérebro social (HERCULANO-HOUZEL, 2005; GAZZANIGA; HEATHERTON, 2005; BOYD; BEE, 2011).

Devido a essa reorganização estrutural, a adolescência seria mais uma fase, além da infância, na qual o ambiente como um todo, bem como os pais podem exercer grande influência sobre os caminhos que o cérebro em reestruturação toma - positiva ou negativamente.

De acordo com Cloutier e Drapeau (2012), o desenvolvimento social do adolescente se dá em três pilares de emancipação que se produz entre os 12 e 18 anos: o processo de socialização, o desenvolvimento da autonomia e das competências sociais. O processo de socialização é definido como a aquisição de ações e comportamentos necessários à adaptação do indivíduo em sociedade. Esse processo não começa e nem termina na adolescência, porém, segundo os autores, ele muda de ritmo nessa fase devido às transformações físicas e mentais que os jovens vivenciam.

A cognição social, segundo Santrock (2014, p. 454), envolve "a forma como os indivíduos conceituam e pensam sobre seu mundo social: as pessoas que eles veem e com quem interagem, suas relações com essas pessoas, os grupos dos quais participam e a forma com quem pensam sobre si mesmos e os outros".

Os autores Cloutier e Drapeau (2012) definem competência social como a capacidade do indivíduo apresentar habilidades sociais, emocionais, cognitivas e comportamentais perante as convivências interpessoais. De acordo com Cloutier e Drapeau (2012, p. 193), algumas das características pessoais assimiláveis a boas competências sociais do adolescente, podem ser assim descritas:

- Geralmente está de bom humor.

- Manifesta um bom senso de humor.

- É relativamente independente e autônomo.

- Interessa-se pelos outros, sabe pedir e dar informações de forma apropriada.

- É capaz de estabelecer e manter relações afetuosas com os outros.

- Integra-se com facilidade em conversas, contribuindo positivamente para alimentá-las.

- Participa de bom grado das atividades de seu meio social.

- Sabe compartilhar e cooperar com os outros.

- Não tenta monopolizar a atenção dos outros. 
- Não enfrenta problemas de solidão ou rejeição social. Pelo seu jeito de ser, incita os outros a escolhê-lo para brincar ou trabalhar.

- Exprime seus gostos e preferências sem dificuldade e é capaz de justificar seus pedidos convenientemente.

- É capaz de encontrar o seu lugar, defender seus direitos e expressar suas necessidades de modo adequado.

- Não se deixa intimidar facilmente.

- Consegue exprimir suas frustrações e sua raiva de forma eficaz, sem perder o controle ou machucar os outros.

- É capaz de superar suas frustrações sem ficar perturbado.

- Consegue resolver problemas interpessoais de forma pacífica.

- É capaz de manifestar compaixão por pessoas que estão passando necessidade.

Embora ainda existam grandes controvérsias a respeito das definições de competência social e aptidões sociais, cada vez mais autores reconhecem a sua importância. A ausência de um vocabulário e de conceitos torna complexa a questão da definição de competência social. Topping, Bremner e Holmes (2002), apoiando-se em Bandura, lembram que um sujeito socialmente competente é aquele que reúne diversas variáveis como a atenção, a retenção, a reprodução motora e a motivação em seus processos de aprendizagem social. Para os autores, a definição atual de competência social seria a capacidade de integração entre pensamento, sentimento e comportamento para a realização de tarefas com resultados sociais valorizados na cultura em que o indivíduo encontra-se inserido. É sabido que existem diferentes tipos de culturas, com grupos diferentes de conceitualizações de competência social, construídas de maneira socialmente distintas.

Apesar disso, existe um consenso na maioria das sociedades, nas quais se pregam atitudes sociais positivas como: evitar prejudicar os outros, contribuir positivamente para o grupo pertencido, para a família, a escola, o local de trabalho e a comunidade em geral. Para Topping, Bremner e Holmes (2002) dentre os comportamentos socialmente competentes se incluem ainda o zelo pela própria saúde e o cuidado em não trazer consequências negativas para os outros. Aqueles que são socialmente competentes lidam melhor com os estresses da vida e se tornam mais resistentes aos estímulos negativos, como a ingestão de drogas, por exemplo. 
Um bom entendimento do universo social em que está inserido depende do grau de evolução da cognição social e são importantíssimos para a adaptação social. A cognição social passa por importantes transformações na adolescência, entre 12 e 18 anos, pois sob a ação do pensamento formal, a compreensão de si mesmo e dos outros é aprimorada. Nessa fase, há um progresso nas inferências e suposições quando comparadas àquelas que faziam na infância. Com maior noção de subjetividade, o adolescente tem consciência inclusive de que seus pensamentos podem ser objeto de atenção e interpretação dos outros, além de compreender que suas opiniões e percepções podem divergir daquelas apresentadas por outras pessoas. Entretanto, nem todos os adolescentes atingem os mesmos patamares de competências sociais. Vários elementos vão determinar o modo como os jovens adolescentes vão se adaptar à sociedade, e precisam ser considerados, como os aspectos biológicos, as questões intelectuais, a família, a escola, as amizades, entre outros (CLOUTIER; DRAPEAU, 2012).

Neste sentido, a aprendizagem de comportamentos interpessoais sofre influências decorrentes das intervenções positivas ou negativas vivenciadas na família, escola e demais contextos sociais. Nesse caso, o desenvolvimento da autoconsciência ajuda a administrar emoções, pois através da consciência autorreflexiva, observa-se e investiga-se o que está sendo observado, incluindo as emoções. Apesar de que as emoções ocorram normalmente de modo inconsciente, no momento em que essa emoção passa para a consciência tem assinalado seu registro como tal no córtex frontal e então se passa a avaliar essa reação, decidindo ou não abandonar os sentimentos, mudando ou não de perspectiva e estado de espírito. Assim, as constantes aprendizagens permitem não só conhecer e lidar com as próprias emoções, mas também reconhecer emoções nos outros, o que contribui para desenvolver atitudes como empatia e altruísmo e tornando os indivíduos mais aptos ou inaptos para um bom convívio em grupo (GOLEMAN, 2012).

Nessa mesma direção, Damásio (2012, p. 128) preconiza que as emoções “[...] desempenham uma função na comunicação de significados a terceiros e podem ter também o papel de orientação cognitiva [...]". Entretanto, importa lembrar que, de acordo com Papalia e Feldman (2013), já na segunda infância, a criança passa a incorporar em sua autoimagem uma compreensão mais acurada de como é percebida pelos outros, começando a desenvolver a autoconsciência. Nesta idade começa a entender e regular, ou controlar, os próprios sentimentos.

Tanto a infância como a adolescência são períodos fundamentais para que cada um possa se habilitar e aprender a governar sua vida com sucesso emocional básico. Isso mostra 
que a linguagem não é só verbal, mas também corporal: nossos gestos, atitudes, semblantes e comportamentos expressam não só pensamentos e sentimentos, mas são objetos de interpretação, gerando uma reação por parte dos outros. Para Gazzaniga e Heatherton (2005), informações compõem o comportamento não verbal, ocorrendo uma comunicação por meio de expressões faciais, deixas vocais e movimentos corporais, o que orienta a interação social.

No caso mais específico dos adolescentes, em que ainda existe o processo de desenvolvimento de um cérebro proativo e gerenciador de suas próprias condutas, eles se encontram vulneravelmente expostos aos mais variados ambientes positivos ou negativos. Um indivíduo adulto difere de um indivíduo adolescente no sentido de que é mais eficaz no elemento do pensamento, isto é, sabem o que devem fazer para serem considerados socialmente competentes em determinadas situações.

Segundo Topping, Bremner e Holmes (2002), a escola é um dos ambientes sociais com demandas que exigem muito da competência social. Contudo, a escola, apesar de ocuparse com a aquisição de conhecimento, não tem planejado e desenvolvido um processo educativo que priorize a formação de atitudes e convicções, e as preocupações com a disciplina escolar e com os conteúdos programáticos não são suficientes para formar o cidadão (PAVIANI, 2008).

Santos e Primi (2014, p. 11) defendem que "[...] o ato de aprender conteúdos curriculares não envolve apenas competências ligadas ao raciocínio e à memória, mas exige também motivação e capacidade de controlar a ansiedade e outras emoções". Nessa mesma linha de pensamento, Tough (2014) menciona que o efeito de uma boa educação transpõe o domínio do conhecimento científico, também atinge os âmbitos emocional e psicológico do individuo.

Conforme Sastre e Moreno (2003), os conflitos fazem parte do cotidiano escolar e podem ser amenizados quando aprendemos a identificar os sentimentos. O mal-estar, a insatisfação referente aos colegas, revela o desequilíbrio emocional existente em determinada turma, no grupo ou no aluno, dessa forma, seria prudente um trabalho de identificação das causas e a construção de hipóteses de solução; não apenas constatar, mas abrir espaço para discussão.

Mas como lidar com a construção da competência social dos alunos adolescentes nas escolas? Baseando-se na ideia de que competência social significa uma consciência do que fazer ou não fazer, sabe-se que os indivíduos não são socialmente competentes em todas as situações. Em relação aos professores e ao papel da escola como ambiente de mediação, há 
um grande desafio por parte dos professores em contribuir no processo de construção da competência social de seus alunos.

Tomando como ponto de partida as diferentes origens desses indivíduos fora da escola e que são carregados de pensamentos, sentimentos, habilidades e comportamentos que variam de uma situação para outra, avaliar o comportamento do aluno adolescente se torna muito difícil, no que diz respeito às condutas socialmente competentes. O que esses alunos aprenderam em suas experiências de vida? Quando realmente usam suas habilidades sociais em situações diversas em sala de aula? Quando não estão sendo influenciados pela vergonha, falta de autoestima, mergulhados em autoconceitos negativos trazidos de suas construções de identidades? Como lidam com os estereótipos da adolescência?

Pensando sobre a relação entre cérebro, emoção e comportamento, é possível afirmar que entender o cérebro adolescente significa entender seu comportamento; e entender seu comportamento é o mesmo que entender sua emoção. Ampliando essa visão, é possível inferir que os conhecimentos neurocientíficos, uma vez apresentados aos próprios adolescentes, podem ser meios de amenizar as angústias vivenciadas por eles e, ainda, oferecer condições de proporcionar o autogerenciamento para esses adolescentes.

Em relação aos autoconceitos negativos que muitos possam trazer de sua infância e de relações pessoais, que poderiam ser agentes causadores de seus fracassos escolares, ao entender como se dão os processos de mudanças estruturais ocorridos nessa fase como sono, medo, tédio, entre outros, podem vir a se tornar mais conscientes sobre si mesmos, pois "os autoconceitos também predizem o comportamento" (BOYD; BEE, 2011, p. 462).

Um estudo feito com adolescentes entre 16 e 20 anos, em uma escola secundária de Coimbra, teve como objetivo investigar competências sociais, como cooperação, autocontrole, empatia nesses jovens com o intuito de promover um programa de intervenção para promoção dessas competências sociais. O estudo quali-quantitativo envolveu entrevistas, questionários e avaliações de competência social. O resultado apresentou mudanças positivas para os estudantes que participaram do estudo: eles compreenderam a teoria relacionada à competência social e houve transposição da aprendizagem para outros contextos de relacionamentos interpessoais (em casa, na escola, na intimidade, familiares, amigos), a partir do que se pode concluir que o conhecimento social se traduziu em desempenho socialmente competente.

Os autores da pesquisa sugerem a implementação desses programas de intervenção nas escolas, sustentando a ideia de que os adolescentes realmente podem ser modificados pelo treino de suas competências sociais, contribuindo para o autoconhecimento e para relações 
interpessoais positivas (LOUREIRO, 2011). Nessa perspectiva, Goleman (2012, p. 26) almeja chegar " [...] o dia em que o sistema educacional incluirá como prática rotineira a instilação de aptidões humanas essenciais como autoconsciência, autocontrole e empatia e das artes de ouvir, resolver conflitos e cooperar".

Adolescentes aumentam a autoestima e o autoconceito quando tem um desempenho competente em domínios de relevância para o seu self. Por isso, devem ser encorajados a valorizar seus domínios de competência (SANTROCK, 2014). Logo, esses conhecimentos sobre neurociências podem vir a contribuir positivamente para as práticas em sala de aula à medida que uma melhor compreensão das dimensões cognitivas, motoras, afetivas e sociais, pode influenciar no redimensionamento do sujeito aprendente e nas suas formas de interferir nos ambientes pelos quais perpassa. Isso pode ser concebido como fomento ao automonitoramento, característica de personalidade que descreve a extensão com que as pessoas monitoram e alteram seu comportamento de acordo com as deixas situacionais, num processo de autorregulação.

\section{Memória e mudanças conceituais}

Para Moraes (2008) é necessário uma educação que promova a evolução do sujeito na sociedade, que construa um diálogo com o cotidiano, levando em consideração práticas individuais e coletivas, de forma que os fenômenos do dia-a-dia sejam apropriados pelo indivíduo se tornem conhecimento e gerem transformações. Pozo e Gómez Crespo (2009), no que diz respeito ao ensino de ciências, salientam que quando compreendemos e damos sentido às coisas, os dados se tornam mais fáceis de serem retidos. Uma pessoa concretiza um conceito quando consegue significar uma informação que lhe é apresentada; seria como traduzir algo para suas próprias palavras. Como comentado anteriormente, essa tentativa de dar significados apoia-se em conhecimentos prévios para concretizar uma aprendizagem significativa. Somente uma modificação nos conhecimentos prévios caracterizará uma mudança conceitual.

É importante valorizar as concepções dos alunos porque a reinterpretação do cotidiano se dá à medida que o conhecimento novo apoia-se em conhecimentos já existentes do estudante. Quanto à exploração do conhecimento científico, é imprescindível contextualizar e problematizar a fim de facilitar a incorporação de modo estável nas representações que os alunos já possuem ou, ainda, de alterar essas representações (BORGES, 2008). 
Assim, é possível que o estudante atinja a aprendizagem significativa, pois seleciona as informações relevantes para ele e as organiza mentalmente, integrando-as aos seus conhecimentos prévios. Daí a relevância do uso desses conhecimentos como "ganchos" para a construção de novas redes neurais, o que é possível através da plasticidade cerebral, que consiste no conjunto de modificações estruturais e/ou funcionais de conexões neurais que possibilitam a aquisição de novos padrões comportamentais.

Essas modificações são dinâmicas e passam por mudanças constantes no cérebro humano, considerando as funções de aprendizado e experiências individuais de cada um. Para Relvas (2009, p. 16),

[...] plasticidade cerebral é a capacidade de o sistema nervoso alterar o funcionamento do sistema motor e perceptivo baseado em mudanças no ambiente, por meio da conexão e da (re) conexão das sinapses nervosas, organizando e (re) organizando as informações dos estímulos motores e sensitivos.

Conforme Lent (2008, p. 126) “um simples 'gatilho' (um fragmento da informação inicial) dispara o processo [de evocação] mais rapidamente e 'reconstrói' tudo como se fosse a primeira vez, recuperando os arquivos da memória quando necessário". Relvas (2009) diz que a aprendizagem acontecerá se o indivíduo encontrar referências em seus arquivos já formados para a nova informação apresentada.

Assim, os conhecimentos neurocientíficos podem auxiliar o adolescente a compreender o que está vivenciando, pois podem interferir na construção de memórias declarativas (MD), as quais envolvem o registro de fatos, eventos ou acontecimentos de nossa vida. A MD é constituída por dois tipos de memória: a memória semântica (MS), a qual está relacionada com o vocabulário básico e o conhecimento geral de mundo, e a memória episódica (ME), que se refere a eventos que assistimos ou dos quais participamos, por exemplo: lembranças de situações familiares, das interações com professores e colegas, de um filme ou de algo que lemos ou que nos contaram, permitindo "uma viagem mental no tempo" (EYSENCK; KEANE, 2007; EYSENCK, 2011).

Ao agregar conhecimento científico ao conhecimento prévio dos estudantes, oportuniza-se a ampliação das memórias semânticas (IZQUIERDO, 2011). Nessa situação, o cérebro faz a análise semântica e o significado de qualquer conceito depende de suas conexões com outros conceitos, sendo ativada a memória semântica. Este tipo de memória envolve o uso de léxico mental como um dicionário e pode ser concebida como o conhecimento organizado que uma pessoa possui sobre as palavras e demais símbolos verbais, bem como sobre as relações entre eles. 
Paralelamente, a exploração do conhecimento científico pode oferecer a formação de memórias episódicas positivas quando considerada a possibilidade de ampliar também a compreensão sobre os acontecimentos e comportamentos do próprio adolescente, trazendo um melhor entendimento de uma experiência subjetiva. A ME é dependente

[...] de um tipo especial de consciência que todos os humanos adultos, saudáveis podem identificar. É o tipo de consciência experimentada quando se pensa retrospectivamente sobre um momento específico de nosso passado, conscientemente, relembrando algum episódio ou estado anterior como foi experienciado. (EYSENCK, 2011, p. 129).

A ME pode, ainda, ser concebida como um catálogo de experiências, ao qual recorrese quando necessário. Essas memórias podem se acumular e consolidar para formarem a base da memória semântica, isto é, permite o conhecimento sobre as coisas e sobre o mundo e, inclusive, sobre os próprios indivíduos.

A exposição de conhecimentos científicos na área das neurociências, quando articulada ao cotidiano do aluno, pode interferir no autoconhecimento e/ou autopercepção, uma vez que os conceitos estão envolvidos na percepção, na aprendizagem, na memória e no nosso uso da linguagem e desempenham a função de prover uma maneira eficiente de representar o conhecimento de mundo, permitindo fazer previsões acuradas, facilitar a comunicação com outras pessoas e a compreensão e exposição do "próprio eu". Os conceitos ligam experiências às interações atuais, se revelam como conhecimento e ajudam a entender e agir diante do que está acontecendo. (EYSENCK; KEANE, 2007).

\section{Mediação na autopercepção}

Sartório (2006) destaca que os amigos e a escola são ambientes ideais para o aprendizado das decisões emocionais, tanto de si próprio quanto dos outros, e também de adquirir um posicionamento empático utilizando-se de áreas como o córtex orbito-frontal e o córtex temporal-superior que estão diretamente relacionados às habilidades sociais e à tomada de decisões morais.

Segundo Bock, Furtado e Teixeira (2008, p. 181), "atitudes podem ser modificadas a partir de novas informações, novos afetos ou novos comportamentos ou situações." Se crianças e adolescentes ficarem frente a situações problemáticas que exijam decisões de ordem moral, de julgamento de emoções, uma maturação de áreas cerebrais responsáveis por 
essas habilidades lhes será proporcionada. Sendo assim, terão mais chances de se tornarem adultos cooperativos, empáticos e emocionalmente sadios. (SARTÓRIO, 2006).

Quanto maior a competência dos adolescentes e do apoio que recebem, menor será a chance de um envolvimento em comportamentos arriscados e maior a preocupação com sua saúde e seu desempenho escolar. Sendo assim, o jovem adquire uma maior preocupação consigo mesmo e com os outros nas diversas situações que enfrenta.

Conforme Boyd e Bee (2011, p. 457),

Os adolescentes estão conscientes da necessidade de transição para a vida adulta, e eles dão muitos passos para essa meta sozinhos. Todavia eles precisam de adultos para abrir caminho e dar-lhes apoio quando seus passos para a maturidade se revelam equivocados, quer esse apoio ocorra no contexto de ritos de passagem formais quer de maneiras informais.

Mas como desenvolver um sentimento de autoconfiança em um jovem face às demandas da adolescência? O que fazer para auxiliar os jovens a melhor lidar com os processos interacionais? Para Cloutier e Drapeau (2012), além das vivências anteriores, o trabalho de estimulação por parte dos professores é condição imprescindível para alavancar o processo de autoconfiança do jovem, não só em face à aprendizagem, mas também diante de suas relações sociais.

O professor deve manifestar sempre o interesse pelos seus alunos, pois a relação educativa é, antes de tudo, social e emocional, estimulando adoções de atitudes pró-sociais de modo contínuo em sala de aula, como respeito pelo próximo, cooperação, justiça, entre outros (CLOUTIER; DRAPEAU, 2012). Tais aspectos, dentro de um processo de autopercepção e autogerenciamento, vêm ao encontro da relação entre os conhecimentos da neurociência e os processos de compreensão por parte dos adolescentes sobre as mudanças estruturais pelas quais perpassam, como possibilidade de desenvolverem estratégias para lidarem com as diferentes situações que vivenciam. Segundo Gardner (2005), uma pessoa que conhece sua própria mente tem chance de modificá-la efetivamente e esse conhecimento pode ser entendido como um empreendimento pessoal.

Interessante é que a neurociência tem sido objeto de atenção da mídia e muitos de seus achados são direcionados para adolescentes, seja por meio da educação informal, seja por meio de artefatos culturais como revistas, jornais, televisão, Internet, entre outros. Nesse sentido, uma pesquisa realizada por Nunes (2014) aponta que dentre 52 edições da revista Mundo Estranho, considerando o período entre 2010 e 2013, 28 delas (53,8\%) traziam artigos relacionados à neurociência, totalizando 35 artigos. Os temas eram atuais como por exemplo: 
neurônios espelho, plasticidade cerebral, neuromarketing e comportamento, sendo expostos com linguagem acessível e conectados ao cotidiano dos leitores infanto-juvenis.

Em outra perspectiva, assim como a descrição de eventos neurobiológicos no discurso midiático conduz percepções acerca de como funcionamos produzindo significados e representações que atingem o self, na educação formal, o livro didático pode desempenhar o mesmo papel. Entende-se por educação formal aquela organizada e sequenciada, que é proporcionada pela escola com estrutura e plano de estudo, com papéis definidos para quem ensina e para quem aprende. Nesse contexto, entram os livros didáticos como ferramentas na concretização do currículo na tríade professor- conteúdo-aluno.

Sabendo que a função do livro didático é de democratizar o ensino através da divulgação científica e que este é um mediador entre diferentes saberes que circulam pelo ambiente escolar colaborando para a seleção e organização de conteúdos e métodos de ensino, torna-se inquestionável o seu valor e utilidade quando se pensa a possibilidade de explorar a relação entre neurociências e o cotidiano do aluno adolescente.

Considerando, ainda, que, para muitas crianças e jovens, a escola é o único lugar de acesso ao conhecimento científico e esse é de extrema importância para que o aluno compreenda melhor o mundo em que vive através da relação entre ciência e cotidiano, é imprescindível a atualização dos conteúdos apresentados nos livros didáticos. No entendimento de Xavier, Freire e Moraes (2006, p. 276), “[...] o livro didático é ferramenta de ensino-aprendizagem e suporte para a organização do currículo na maioria das instituições de ensinos Fundamental e Médio do país". Os autores salientam que esta ferramenta para ser "fonte viva de sabedoria", precisa estar atualizada e amenizar ou até mesmo diminuir o abismo entre Ciência e cidadania (XAVIER; FREIRE; MORAES, 2006).

Daí a importância da elaboração do livro didático e de conhecer bem esse material para poder utilizá-lo adequadamente. Partindo dessa premissa, o Ministério da Educação e Cultura (MEC) criou o Programa Nacional do Livro Didático (PNLD) (BRASIL, s/d.) baseado nas orientações educacionais dos Parâmetros Curriculares Nacionais, complementados para o Ensino Médio (PCNEM) (BRASIL, 2000), definidos pela Lei de Diretrizes e Bases da Educação Nacional 9394/96 e regulamentados pelas Diretrizes do Conselho Nacional da Educação. Baseado nisso, o MEC selecionou uma comissão de especialistas para avaliar a qualidade dessas obras de diferentes autores e editoras com o objetivo de atuar positivamente nos processos de definições do padrão de qualidade dos manuais didáticos que circulam nas escolas. E ainda, em 2004, criou o Programa Nacional do 
Livro Didático para o Ensino Médio (PNDLEM), sendo que a distribuição de livros de Biologia para o ensino médio iniciou em 2007.

A preocupação do MEC com a abordagem de temas atuais é demonstrada no momento em que reconhece que a sociedade contemporânea demanda sensibilidade e atenção por parte da escola para com as profundas e rápidas mudanças com que os jovens se defrontam no campo da cultura, da ciência, da tecnologia, das artes e do trabalho. Muitos pesquisadores acadêmicos vêm se dedicando a investigar a qualidade das coleções de livros didáticos, apontando suas deficiências e sugerindo melhorias em sua qualidade (FRACALANZA; MEGID NETO, 2006).

Diante de uma ciência em constante evolução, pesquisas realizadas por Xavier, Freire e Moraes (2006) avaliaram que o padrão de atualização dos livros didáticos de biologia não apresenta temas essenciais para realizar mudanças conceituais. Para Fracalanza, Amaral e Gouveia (1986), o livro didático seria um agente cultural que, além de ser ligado ao currículo da escola, seleciona conteúdos considerados relevantes às séries escolares, e em uma sequência considerada adequada para favorecer a didática.

Nesse cenário, no que se refere aos avanços das neurociências, a inclusão de temas enfatizando a questão da adolescência e suas mudanças comportamentais sob a ótica neurocientífica podem colaborar para que se obtenha um esclarecimento maior a respeito da fase que os adolescentes vivenciam, oportunizando adolescentes estes refletirem acerca de si mesmos e sobre seus comportamentos. Esta visão pode se concretizar na existência de textos complementares referentes a esse assunto.

Ainda que haja carência no livro didático mediante a necessidade de explorar conteúdos de cunho neurocientífico, a escola pode ampliar essa possibilidade. Dada tal limitação, essa instituição tem como alternativa os programas de intervenção. Tais programas têm como ideia principal, projetar para o futuro a intencionalidade da ação humana, neste caso, a intervenção, por exemplo, de um pesquisador na realidade escolar. Um projeto de intervenção apresenta, em sua essência, a viabilidade para investigação, aprofundamento teórico, produção de conhecimento e intervenção na realidade da escola. Desse modo, delinearia a intencionalidade de ações a serem implementadas com relação direta entre a realidade escolar, o objeto de investigação e a proposição de intervenção.

Os benefícios advindos de propostas nesse sentido podem desencadear um processo mais profundo do movimento percepção-reflexão-compreensão-autorreorganização em adolescentes. Interessa ressaltar que intervenções que visam aprimorar o desenvolvimento das competências exemplificadas acima, acontecem influenciadas pela idade e se tornam 
flexíveis, em especial, na adolescência. Essa flexibilidade cerebral necessária para promover o autocontrole e a autopercepção, como comentado anteriormente, está intimamente relacionada à maturação do córtex pré-frontal na adolescência. A neurociência propõe, inclusive, embasamento para desenvolver estratégias que podem sustentar as carências do desenvolvimento dessas capacidades em crianças expostas a ambientes com pouca oferta de estímulos.

Esses sujeitos, muitas vezes, podem trazer de sua infância e de relações pessoais autoconceitos negativos, que poderiam ser agentes causadores de seus fracassos escolares. Sendo assim, é possível valorizar a contribuição de conhecimentos neurocientíficos na construção perceptual desse aluno adolescente acerca de si mesmo como sujeito autorreorganizador. Isso pode trazer uma maior segurança no ambiente escolar e nas relações sociais, pois o educador está frequentemente agindo nas modificações cerebrais de seu aluno, o que leva a novas aprendizagens. Como destaca Johnson (2008), a neurociência ao nos ensinar sobre o modo como geramos nossos comportamentos, pode colaborar para um novo tipo de autoconhecimento, sendo um conhecimento que transforma, tanto quanto informa. , são saberes que podem contribuir para a construção da competência social desses indivíduos.

Os conhecimentos neurocientíficos que descrevem as transformações fisiológicas em que esse cérebro adolescente se encontra podem ter muito a contribuir com o ambiente escolar no que diz respeito à construção perceptual do aluno e às formações de suas competências sociais, aprimorando seus entendimentos.

Exemplificando, ao explorar o tema emoções, é possível oferecer aos estudantes a oportunidade de conhecer como as emoções e os sentimentos, ao envolver os estados físico e psicológico, afetam o comportamento. Conforme Mayer e Salovey (1997), esse conhecimento pode contribuir para que se desenvolva a Inteligência Emocional, a qual envolve a capacidade de perceber acuradamente, de avaliar e de expressar emoções; a capacidade de perceber e/ou gerar sentimentos quando eles facilitam o pensamento; a capacidade de compreender a emoção e o conhecimento emocional; e a capacidade de controlar emoções para promover o crescimento emocional e intelectual. Esses estudantes poderão vir a melhor desenvolver a autoconsciência (identificar emoções em si mesmo e nos outros e administrá-las assertivamente), a autogestão (gerenciar as próprias emoções, superando sentimentos negativos e se recuperando com maior facilidade dos reveses inerentes à vida), a consciência social (como empatia com o outro, perceber seu sentimento, ser altruísta) e a administração de relacionamentos (determinada por saber lidar com as emoções alheias, envolvendo popularidade, liderança e eficiência interpessoal). 
O conhecimento sobre o funcionamento do cérebro oportuniza aprimorar nossos comportamentos, pois amplia nossas possibilidades de entendimento das bases biológicas da percepção pessoal, da cognição social e do comportamento interpessoal (RATEY, 2002; GAZZANIGA; HEATHERTON, 2005). Para o adolescente, saber como seu cérebro funciona e as transformações fisiológicas e psicológicas que estão ocorrendo nessa fase, podem vir a contribuir para uma otimização em seu desempenho escolar, já que, à medida que compreende, poderá se tornar mais proativo em suas atividades estudantis, bem como melhorar sua competência social.

Dentro desse raciocínio, quando os alunos não possuem esse tipo de conhecimento, é necessário buscar e/ou reorientar as estratégias didáticas, dispondo de conhecimentos conceituais adequados. Baseados no fato de que a compreensão do cérebro possibilita uma mudança na percepção de si mesmo e da realidade, Santos e Velasques (2012) realizaram um estudo com o objetivo de conscientizar adolescentes em medidas socioeducativas sobre suas vidas e condições em que viviam. O método foi realizado por meio de cinco encontros semanais intitulados "conversando com seu cérebro". Foram utilizadas ferramentas como palestras, recursos visuais, peças do cérebro com suas funções para apresentar aos adolescentes o funcionamento cerebral de forma didática, sendo que registros qualitativos das percepções adolescentes evidenciaram a grande contribuição do entendimento do funcionamento cerebral no auxílio ao jovem de reconhecer a si mesmo e no interesse notório que a maioria apresentou no que diz respeito à relação deles com os outros, com a lei e a comparação entre como são e como funcionam.

Achados como esses colaboram para fundamentar a importância da escola no desenvolvimento da competência social dos estudantes, inclusive nos comportamentos violentos, que causam tanta preocupação e temor. O termo "violência escolar" se refere aos comportamentos agressivos e antissociais, incluindo conflitos interpessoais, danos ao patrimônio, atos infracionais, entre outros. Por outro lado, muitos desses episódios dependem de fatores externos, cujas intervenções podem ultrapassar as competências e capacidades desses estabelecimentos de ensino e de seus funcionários. Porém, o ambiente escolar pode trazer grandes benefícios e soluções. Santrock (2014), embasado nos estudos de Olweus, menciona um programa de intervenção com o objetivo de reduzir o bullying em jovens de 6 a 15 anos. Funcionários da escola foram instruídos a melhorar as relações entre pares e tornarem a escola mais segura. Segundo o autor, quando implantado de maneira correta, o programa reduz em até $70 \%$ o bullying. 


\section{Considerações finais}

Como é possível perceber, a fase da adolescência é marcada pelo desenvolvimento biológico e pela mediação dos contextos sociais, o que dá origem à complexidade característica dessa fase da vida. Afinal, na busca de uma identidade junto a alterações do corpo, da mente, da personalidade, dos laços afetivos e círculos sociais, surgem angústias e conflitos que precisam ser gerenciados de modo autônomo.

Uma escola que se compromete a propiciar situações que colaborem para o desenvolvimento de competências cognitivas, afetivas e comportamentais no aluno, deverá focar na qualidade de práticas eficazes. E, a partir da discussão proposta, faz-se necessário construir pontes entre a neurociência e a prática educacional. Um esclarecimento a respeito de como o cérebro funciona e o que acontece no sistema nervoso durante a fase da adolescência pode vir a contribuir para que os estudantes aprofundem a compreensão das dimensões cognitivas, motoras, afetivas e sociais, que constituem sua identidade.

Nesse sentido, defende-se a possibilidade de ampliar a contribuição na educação formal, no processo de construção da autopercepção dos adolescentes, tendo, para isso, conteúdo científico de neurociências explorado no livro didático de biologia como ferramenta pedagógica de trabalho.

Paralelamente, percebe-se nos projetos de intervenção outra alternativa pedagógica, sendo que esses, oferecem acesso a espaços que visem discutir, propiciar diálogos entre pares, promover a reflexão tomando como fundamento informações científicas qualificadas, transmitidas em linguagem adequada sobre seus comportamentos..

Isso contribuiria para melhorar as aptidões de autogerenciamento e interação dos jovens, o que poderia vir a promover relações mais sadias, permitindo, ainda, ao adolescente um maior envolvimento ao determinar suas necessidades, avaliar o modo como estão sendo satisfeitas e identificar possibilidades de administrar as demandas características da fase que vivencia. Conhecer o próprio cérebro levaria o adolescente a viver a adolescência com mais tranquilidade.

\section{Referências}

BOCK, Ana Mercês Bahia; FURTADO, Odair; TEIXEIRA, Maria de Lourdes Trassi.

Psicologias: uma introdução ao estudo de psicologia. São Paulo: Saraiva, 2008. 
BORGES, Regina Maria Rabello. Repensando o ensino de ciências. In: MORAES, Roque (Org.). Construtivismo e ensino de ciências: reflexões epistemológicas e metodológicas. Porto alegre: EDIPUCRS, 2008.

BOYD, Denise; BEE, Helen. A criança em crescimento. Porto Alegre: Artmed, 2011.

BRASIL. Lei Federal n. 8.069, de 13 de julho de 1990: Dispõe sobre o estatuto da criança e do adolescente e dá outras providências. Brasília, 1990.

BRASIL. Parâmetros Curriculares Nacionais - Ensino Médio. Brasília: MEC/SEF, 2000.

BRASIL. Programa Nacional do Livro Didático para o Ensino Médio - PNLEM, Brasília: MEC. Disponível em: http://portal.mec.gov.br/component/content/article?id=13608. Acesso em: 20 abr. 2012.

CLOUTIER, Richard; DRAPEAU, Sylvie. Psicologia da adolescência. Petrópolis: Vozes, 2012.

DAMÁSIO, António R. O erro de Descartes: emoções, razão e o cérebro humano. 3. ed. São Paulo: Companhia das Letras, 2012.

EYSENCK, Michael W. Memória semântica e conhecimento armazenado. In: BADDELEY, Alan; ANDERSON, Michael C.; EYSENCK, Micahel W. Memória. Porto Alegre: Artmed, 2011.

EYSENCK, Michael W.; KEANE, Mark T. Psicologia cognitiva: um manual introdutório. Porto Alegre: Artmed, 2007.

FRACALANZA, Hilário; MEGID NETO, Jorge (Org.). O livro didático de ciências no Brasil. Campinas: Komedi, 2006.

FRACALANZA, Hilário; AMARAL, Ivan do; GOUVEIA, Mariley Simões Floria. O ensino de ciências no primeiro grau. 4. ed. São Paulo: Atual, 1986.

GARDNER, Howard. Mentes que mudam: a arte e a ciência de mudar as nossas idéias e as dos outros. Porto Alegre: Artmed/Bookman, 2005.

GAZZANIGA, Micahel S.; HEATHERTON, Todd. Ciência psicológica: mente, cérebro e comportamento. Porto Alegre: Artmed, 2005.

GOLEMAN, Daniel. Inteligência emocional: a teoria revolucionária que define o que é ser inteligente. Rio de janeiro: Objetiva, 2012.

HERCULANO-HOUZEL, Suzana. O cérebro em transformação. Rio de Janeiro: Objetiva, 2005.

IZQUIERDO, Iván. Memória. 2. ed. Porto Alegre: Artmed, 2011.

JOHNSON, Steven. De cabeça aberta: conhecendo o cérebro para entender a personalidade humana. Rio de Janeiro: Jorge Zahar, 2008. 
LENT, Roberto. Neurociência da mente e do comportamento. Rio de Janeiro: Guanabara Koogan, 2008.

LOUREIRO, Cândida Rosalinda Exposto Costa. Competências sociais de estudantes do ensino secundário: construção, implementação e avaliação de um programa de intervenção. Tese (Doutorado em Ciências de Enfermagem). Instituto de Ciências Biomédicas Abel Salazar, Universidade do Porto, Porto, POR, 2011.

MAYER, John D.; SALOVEY, Peter. What is emotional intelligence? In: SALOVEY, Peter; SLUYTER, David J. (Org.). Emotional development and emotional intelligence: implications for Educators. New York: Basic Books, 1997. p. 3-31.

MELO, Maria Cristina Henares; CRUZ, Gilmar de Carvalho. Adolescência e estigma no cotidiano escolar: reflexões à luz de Goffman e Bordieu. In: Programa de Pós-Graduação em Educação da UCS (Org.), IX ANPED SUL: SEMINÁRIO DE PESQUISA EM EDUCAÇÃO DA REGIÃO SUL. Anais,. Caxias do Sul: UCS, 2012.

MORAES, Roque. É possível ser construtivista no ensino de Ciências? In: MORAES, Roque. (Org.). Construtivismo e ensino de ciências: reflexões epistemológicas e metodológicas. Porto Alegre: EDIPUCRS, 2008.

NUNES, Melissa Orlandin. Divulgação científica da neurociência: uma possibilidade de contribuir para a autopercepção na infância. Dissertação (Mestrado Educação em Ciências: Química da Vida e Saúde). Universidade Federal do Rio Grande, Rio Grande, RS, 2014.

PAPALIA, Diane E. ; FELDMAN, Ruth Duskin. Desenvolvimento humano. 12. ed. Porto Alegre: Artmed. 2013.

PAVIANI, Jayme. Interdisciplinaridade: conceitos e distinções. Caxias do Sul: EDUCS, 2008.

POZO, Juan Ignacio; GÓMEZ CRESPO, Miguel Angelo. A aprendizagem e o ensino de ciências: do conhecimento cotidiano ao conhecimento científico. 5. ed. Porto Alegre: Artmed, 2009.

RATEY, John J. O cérebro: um guia para o usuário. Rio de Janeiro: Objetiva, 2002.

RELVAS, Marta Pires. Fundamentos biológicos da educação: despertando inteligências e afetividade no processo de aprendizagem. 4. ed. Rio de Janeiro: Wak, 2009.

SANTOS, Daniel; PRIMI, Ricardo. Desenvolvimento socioemocional e aprendizagem escolar: uma proposta de mensuração para política públicas. São Paulo: OCDE, Instituto Ayrton Senna, Secretaria de Educação do Rio de Janeiro, 2014.

SANTOS, Flávio Roberto de Carvalho; VELASQUES, Bruna. Neurociências: contribuição para adolescentes em Medida Sócioeducativa. I CONGRESSO INTERNACIONAL INTERDISCIPLINAR EM CIÊNCIAS SOCIAIS E HUMANIDADES. Anais... Niterói: UFF, 2012. 
SANTROCK, John W. Adolescência. 14. ed. Porto Alegre: AMGH, 2014.

SARTÓRIO, Rodrigo. Neurociência e comportamento na educação de criança e adolescente. Florianópolis: Cesusc, 2006.

SASTRE, Genoveva; MORENO, Monserrat. O significado afetivo e cognitivo das ações. In: ARANTES, Valéria Amorim (Org.). Afetividade na escola: alternativas teóricas e práticas. São Paulo: Summus, 2003.

TOPPING, Keith, BREMNER, William; HOLMES, Elizabeth A. Competência social: a construção social do conceito. In: BAR-ON, Reuven; PARKER, James D. A. Manual de inteligência emocional: teoria e aplicação em casa, na escola e no trabalho. Porto Alegre: Artmed, 2002.

TOUGH, Paul. Uma questão de caráter: por que a curiosidade e a determinação podem ser mais importantes que a inteligência para uma educação de sucesso. Rio de Janeiro: Intrínsica, 2014.

XAVIER, Márcia Cristina Fernandes; FREIRE, Alexandre de Sá; MORAES, Milton Ozório. A nova (moderna) biologia e a genética nos livros didáticos de biologia no ensino médio.

Ciência e Educação, 12 (3), 275-289, 2006.

Dr ${ }^{a}$ Mauren dos Santos Oliveira

Universidade Federal do Rio Grande - Brasil Graduada em Ciências Biológicas Licenciatura e Bacharelado Mestre em Aquicultura Doutoranda no Programa de Pós- Graduação em Educação em Ciências: Química da Vida e Saúde Universidade Federal do Rio Grande; Rio Grande/RS E-mail: maurenoliveira@yahoo.com.br

\section{Dr $^{a}$ Fernanda Antoniolo Hammes de Carvalho}

Universidade Federal do Rio Grande - Brasil Graduada em Ciências, habilitação em Biologia Mestre em Letras Doutora em Educação Pós-doutora em Educação em Ciências: Química da Vida e Saúde Grupo de Pesquisa em Educação Profissional e Tecnológica E-mail: fahc.rg@gmail.com

Recebido em: 29 de março de 2017 Aprovado em: 14 de abril de 2017 